\title{
Cor triatriatum: A rare congenital cardiac disease in differential diagnosis
}

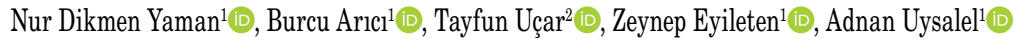 \\ ${ }^{1}$ Department of Cardiovascular Surgery, Ankara University School of Medicine, Ankara, Turkey \\ ${ }^{2}$ Department Pediatric Cardiology, Ankara University School of Medicine, Ankara, Turkey \\ Received: August 02, 2018 Accepted: October 13, 2018 Published online: April 24, 2019
}

\section{ABSTRACT}

Cor triatriatum is a rare congenital cardiac anomaly which requires an urgent surgical repair. Herein, we report an infant with the diagnosis of cor triatriatum sinistrum and to highlight the importance of early differential diagnosis in congenital heart diseases.

Keywords: Congenital, cor triatriatum sinistrum, heart disease.

Congenital heart diseases can be difficult to diagnose in infants, as they often present with non-specific symptoms. Cor triatriatum is among the rarest of all congenital cardiac anomalies ( 0.1 to $0.4 \%$ of all congenital cardiac malformations) and is often a hemodynamically mild incidental finding. ${ }^{[1]}$

Herein, we report an infant with the diagnosis of cor triatriatum sinistrum and to highlight the importance of early differential diagnosis in congenital heart diseases.

\section{CASE REPORT}

A four-month-old female infant with cough, rhinorrhea, and mild dyspnea was admitted to the emergency department and diagnosed with a viral illness. Chest radiograph showed moderate cardiomegaly and mild prominence of pulmonary vasculature. She was referred to the pediatric cardiology department. After examination, electrocardiogram showed sinus tachycardia with right axial deviation and right ventricular hypertrophy. Echocardiogram revealed the diagnosis of cor triatriatum sinistrum. An urgent surgical repair was decided (Figure 1). A written informed consent was obtained from each parent.

The surgical procedure included resection of the membrane at the left atrial cavity. A right atrial approach was preferred and cardiopulmonary bypass with mild-to-moderate hypothermia was applied. The early postoperative period was favorable and transthoracic echocardiography showed the complete removal of the left intra-atrial membrane. The postoperative course was uneventful and the patient was discharged five days after the operation.

\section{DISCUSSION}

Cor triatriatum is a rare congenital cardiac anomaly which affects about 0.1 to $0.4 \%$ of all cases with congenital heart disease. First described by Church in 1868, it was described as an additional fibromuscular membrane within the left atrium on autopsy and, then, the entity was specifically named and described in detail by Borst in 1905. ${ }^{[2]}$

A fibromuscular septum divides the left atrium into two chambers and is thought to arise from failed resorption of the common pulmonary vein. The additional membrane can occur within the left atrium (cor triatriatum sinistrum) or, much more rarely, within the right atrium (cor triatriatum dexter). Cor triatriatum is associated with additional congenital heart lesions in $80 \%$ of cases, most commonly atrial septal defects and anomalous pulmonary venous return. ${ }^{[3]}$

Corresponding author: Nur Dikmen Yaman, MD. Ankara Üniversitesi Tip Fakültesi Kalp ve Damar Cerrahisi Anabilim Dalı, 06620 Altındağ, Ankara, Turkey. Tel: +90 312 - 5956084 e-mail: nurdikmen@yahoo.com

\section{Citation:}

Dikmen Yaman N, Arıcı B, Uçar T, Eyileten Z, Uysalel A. Cor triatriatum: A rare congenital cardiac disease in differential diagnosis. Cardiovasc Surg Int 2018;5(3):37-39. 

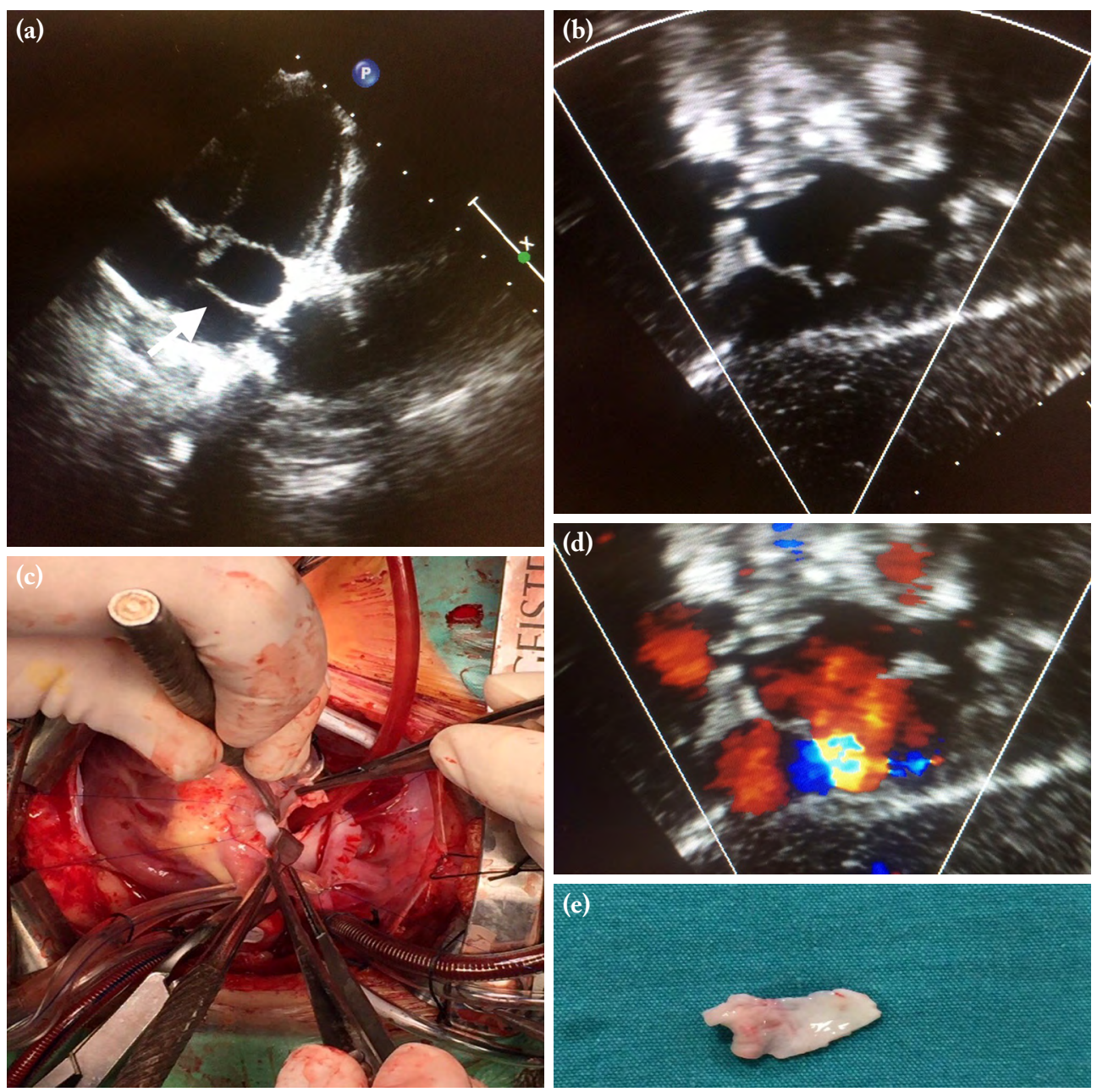

Figure 1. (a, b, d) Echocardiographic and (c) intraoperative images of cor triatriatum sinistrum and (e) image of membrane resected.

The symptom spectrum of the disease correlates with the degree of obstruction caused by the membrane. Larger openings and normal venous return correspond to fewer symptoms. Patients with a significant obstruction are likely to present in infancy with symptoms resulting from pulmonary congestion and pulmonary arterial hypertension. Common presentations include failure to thrive, dyspnea, cyanosis, or even shock. ${ }^{[4]}$ Late presentation in late adulthood may be due to fibrosis and calcification of the orifice. A long-standing turbulent flow through the membrane can cause stenosis or with the development of mitral regurgitation or atrial fibrillation. The symptoms are similar to the symptoms of mitral stenosis. ${ }^{[5]}$

There are various techniques available to identify the pathology. As in our case, echocardiography is diagnostic and can differentiate from other congenital heart lesions, such as pulmonary vein stenosis. More invasive diagnostic studies such as magnetic resonance imaging, computed tomography, and cardiac catheterization can be also used, when echocardiography yields uncertain findings. ${ }^{[6]}$

Recommended treatment depends on symptoms. Mild dyspnea in older patients may improve with diuretics and preload reduction. For those with worsening or severe symptoms, as in our case, surgical correction is often required. Resection of the membrane can be curative with a rare recurrence of symptoms; however, surgical repair appears to have a greater mortality at younger ages ( $<5$ years) and those with severe preoperative heart failure. ${ }^{[7]}$ 
In conclusion, cor triatriatum is a congenital heart disease which usually presents during infancy with failure to thrive mimicking respiratory infections and sepsis. It can be life-threatening and must be rapidly diagnosed. Surgical treatment is often life-saving, even after the development of respiratory failure and shock.

\section{Declaration of conflicting interests}

The authors declared no conflicts of interest with respect to the authorship and/or publication of this article.

\section{Funding}

The authors received no financial support for the research and/or authorship of this article.

\section{REFERENCES}

1. Briasoulis A, Sharma S, Afonso L. A three-dimensional echocardiographic approach to cor triatriatum. Int J Cardiol 2015;180:262-3.
2. Chen Q, Guhathakurta S, Vadalapali G, Nalladaru Z, Easthope RN, Sharma AK. Cor triatriatum in adults: three new cases and a brief review. Tex Heart Inst J 1999;26:206-10.

3. Humpl T, Reineker K, Manlhiot C, Dipchand AI, Coles JG, McCrindle BW. Cor triatriatum sinistrum in childhood. A single institution's experience. Can J Cardiol 2010;26:371-6.

4. McKeag NA, Murphy JC, Dixon LJ. An incidental finding or an unusual cause for a transient ischaemic attack? QJM 2012;105:789-90.

5. Erden EÇ, Erden İ, Kayapınar O. Cortriatriatum sinister with significant pressure gradient in an adult patient. Turk Gogus Kalp Dama 2013;21:143-5.

6. Masui T, Seelos KC, Kersting-Sommerhoff BA, Higgins CB. Abnormalities of the pulmonary veins: evaluation with $M R$ imaging and comparison with cardiac angiography and echocardiography. Radiology 1991;181:645-9.

7. Saxena P, Burkhart HM, Schaff HV, Daly R, Joyce LD, Dearani JA. Surgical repair of cor triatriatum sinister: the Mayo Clinic 50-year experience. Ann Thorac Surg 2014;97:1659-63. 